\title{
Outcome of acute kidney injury: how to make a difference?
}

\author{
Matthieu Jamme $e^{1,2,3^{*}} \mathbb{0}$, Matthieu Legrand ${ }^{4}$ and Guillaume Geri $2,3,5$
}

\begin{abstract}
Background: Acute kidney injury (AKI) is one of the most frequent organ failure encountered among intensive care unit patients. In addition to the well-known immediate complications (hydroelectrolytic disorders, hypervolemia, drug overdose), the occurrence of long-term complications and/or chronic comorbidities related to AKI has long been underestimated. The aim of this manuscript is to briefly review the short- and long-term consequences of AKI and discuss strategies likely to improve outcome of AKI.

Main body: We reviewed the literature, focusing on the consequences of AKI in all its aspects and the management of AKI. We addressed the importance of clinical management for improving outcomes AKI. Finally, we have also proposed candidate future strategies and management perspectives.

Conclusion: AKI must be considered as a systemic disease. Due to its short- and long-term impact, measures to prevent AKI and limit the consequences of AKI are expected to improve global outcomes of patients suffering from critical illnesses.
\end{abstract}

Keywords: Acute kidney injury, Long-term outcome, Chronic kidney disease, Intensive care

\section{Introduction}

Acute kidney injury (AKI) is one of the most frequent organ failure encountered in intensive care units (ICU). Since his first definition by Homer W. Smith in the fifties [1], more than 30 different definitions have been used, leading to a sizeable epidemiological heterogeneity [2] with incidence ranging from 5 [3] to $25 \%$ [4].

Since 2004, three definitions, based on serum creatinine (SCr) and urine output, respectively: RIFLE [5], AKIN [6], and the actual KDIGO classification [7] have been proposed allowing homogenization of AKI definition as well as epidemiological association between AKI and chronic kidney disease (CKD). Based on the most recent KDIGO definition, AKI occurs in more than a third of ICU patients $[8,9]$.

\footnotetext{
*Correspondence: matthieu.jamme@ght-yvelinesnord.fr

1 Service de Réanimation, Hôpital de Poissy, CHI Poissy Saint Germain, 10

rue du champ Gaillard, 78300 Poissy, France

Full list of author information is available at the end of the article
}

\section{Why physicians should worry about AKI?}

Occurrence of AKI represents a sharp prognostic turn for patients by affecting both short- and long-term prognosis.

\section{AKI and global (short and long term) prognosis}

The multinational EPI-AKI study has highlighted that AKI was associated with short-term mortality in a severity-dependent manner $(\mathrm{OR}=2.19$ [1.44-3.35], 3.88 [2.42-6.21] and 7.18 [5.13-10.04] for KDIGO stage 1, 2 and 3 , respectively) [8]. All subgroups of ICU patients seemed to be affected [10-15]. A poor short- and midterm outcome was also observed in patients with subclinical AKI (defined by positive biomarkers of kidney injury but not meeting the current definition of AKI) [16].

Moreover, AKI has been repeatedly associated with poor long-term outcomes [17]. In a large study reporting 1-year outcome of more than 16,000 patients discharged alive from the hospital and who suffered AKI in ICU, five profiles were identified according to the renal status

\section{Springer Open}

(c) The Author(s) 2021. This article is licensed under a Creative Commons Attribution 4.0 International License, which permits use, sharing, adaptation, distribution and reproduction in any medium or format, as long as you give appropriate credit to the original author(s) and the source, provide a link to the Creative Commons licence, and indicate if changes were made. The images or other third party material in this article are included in the article's Creative Commons licence, unless indicated otherwise in a credit line to the material. If material is not included in the article's Creative Commons licence and your intended use is not permitted by statutory regulation or exceeds the permitted use, you will need to obtain permission directly from the copyright holder. To view a copy of this licence, visit http://creativeco mmons.org/licenses/by/4.0/. 
during ICU and hospital stay: patients with early ( $<7$ days from admission) or late ( $>7$ days) sustained recovery, relapse with (relapse no recovery) or without altered renal function at hospital discharge (relapse recovery) and sustained renal failure [18]. Patients with altered renal function at hospital discharge (never reversed or relapse no recovery) had the worst outcome. Interestingly, even patients who apparently recovered from AKI at ICU discharge (based on serum creatinine) but with positive biomarkers of kidney injury had a higher risk of death during the year following ICU discharge. Once again, this suggests that beyond the impact of decrease renal function, kidney damage impacts long-term outcomes [19].

\section{AKI and chronic kidney disease (CKD)}

The end of 2010s has been marked by the publication of several studies that highlighted an association between AKI and subsequent CKD occurrence. Wald et al. have compared 3,769 to 13,598 matched patients treated or not treated with renal replacement therapy (RRT) in ICU and observed a higher incidence of end-stage renal disease with RRT (2.63 vs. $0.91 / 100$ patient-years, hazard ratio $=3.23$ [2.70-3.86]) [20]. In a Swedish national cohort of 97,782 ICU patients, Rimes-Stigare et al. have reported that patients who suffered de novo AKI had an increased risk of CKD (adjusted incidence rate ratio $=7.6$ [95\%CI 5.5-10.4]) and end-stage renal disease (ESRD) (adjusted incidence rate ratio $=22.5$ [95\% CI 12.9-39.1]) compared to patients without AKI during their ICU stay [21]. The same group identified that CKD at ICU admission and severity of AKI was associated with ESRD in 1-year survivors [22]. Similar observations were made in specific subgroups like elderly [23], pediatric [24], diabetic [25], post-cardiac surgery [26], or resuscitated cardiac arrest patients [27].

Interestingly, patients who fully recover at hospital discharge remain at risk of CKD 1 year afterwards, particularly in the case of subsequent episodes of AKI during the ICU stay [18]. Of note, all these studies were retrospective or provided results from electronic administrative datasets with significant risk of bias. A major recent prospective study clarified the association between AKI and CKD. In the Assessment, Serial Evaluation, and Subsequent Sequelae IN Acute Kidney Injury (ASSESS-AKI) Study, a multicenter prospective study comparing 769 patients with or without AKI, the authors observed that an increased urinary albumine-to-creatinine (ACR) ratio at 3 months after discharge was the most predictive biomarker of kidney disease progression $(\mathrm{HR}=1.25$ [1.10-1.43] per doubling of urine $\mathrm{ACR}, \mathrm{P}<0.001)$. Interestingly, in multivariable analysis, AKI occurrence was not associated with kidney disease progression [28]. However, we should not neglect the importance of AKI in the evaluation of renal prognosis regards to the sensitivity analyses performed using the urine protein-to-creatinine ratio instead of urine ACR. In that case, AKI became strongly associated $(\mathrm{HR}=2.53$ [1.21-5.25], $p=0.01$ ) with kidney disease progression. Moreover, $\mathrm{C}$ statistic used to discriminate risk of poor renal outcome was better in the latter ( 0.84 vs 0.79 ).

Our current understanding is that an acute episode leaves an imprint (which is expected to be, biologically, of epigenetic nature) able to promote renal fibrosis $[29,30]$. However, mechanisms leading to CKD in this context are not yet fully understood.

\section{AKI and long-term cardiovascular risk}

In several extensive large cohort studies, AKI has been associated with an increased risk of a cardiovascular events [31-33], especially heart failure. In a recently published meta-analysis, Otudayo et al. reported a 58\%, 40\%, and $15 \%$ increased risk of heart failure, myocardial infarction, and stroke, respectively [34]. Mechanisms leading to cardiovascular events are not elucidated so far. Accelerated atherosclerosis might be a contributing factor [35]. In a translational study performed in 968 adults undergoing cardiac surgery, patients with clinical AKI, and elevated cardiac injury biomarkers at day 1-3 were strongly associated with long-term cardiovascular events. Other mechanisms involving mitochondrial dysregulation have also been suggested. Sumida et al. showed increased cardiomyocyte apoptosis and cardiac dysfunction after renal ischemia reperfusion in a mouse model. The authors also observed a significant increase of mitochondrial fragmentation in cardiomyocytes with an accumulation of an unique fission regulation protein: Drp1 [36].

In contrast, urinary kidney injury biomarkers at day 1-3 were not associated with outcome [37]. These results suggested that AKI was indicative of cardiovascular stress rather than an independent renal pathway. However, an association between the occurrence of cardiovascular events and AKI remaining after adjustment for cardiovascular risk factors and preclinical data argue for a direct impact of AKI on cardiovascular damage [38].

This hypothesis has also been demonstrated in a murine experimental work highlighting the role of the galectin-3 pathway [39]. Prud'homme et al. have evidenced AKI increased galectin-3 expression, which induced cardiac inflammation with macrophage infiltration and cardiac fibrosis resulting in cardiac dysfunction. 


\section{The three critical stages of renal management: before, during, and after AKI (Fig. 1)}

\section{Before AKI: prevent AKI to occur}

The cornerstone of AKI prevention in ICU patients is the management of hemodynamics, including appropriate volume of fluids, the choice of fluids and of vasoactive drugs. Even if the pathogenesis of AKI in ICU patients may rely on different mechanisms $[8,40]$, hemodynamic optimization appears essential to prevent alterations of renal blood flow (RBF) [41].

\section{Hemodynamic management}

Appropriate volume replacement should be performed as early as possible while keeping in mind that fluid overload was reported to be associated with poor prognosis in AKI patients $[42,43]$. This apparent antagonist observation probably highlights the higher severity of AKI patients requiring higher volume of fluids and the critical role of the timing of fluid administration during the course of critical illness. Since the first alarming publications about the nephrotoxicity of artificial colloids [44, 45], although probably less harmful in less severe patients [46], crystalloids are the solutions of choice for ICU patients [47, 48]. Indirect and observational results suggested better renal outcomes with so-called balanced solutes $[49,50]$. This could have been explained by the deleterious effects of hyperchloremia acidosis induced by a highly concentrated solution in chlorine [51]. If these observations could not be verified by the randomized clinical trial SPLIT (relative risk for AKI occurrence within 90 days $=1.04[0.80-1.36], p=0.77)$, the absence of sample size calculation added to the noncontrol administration of the solutes before admission to ICU limited the interpretation of this results [52]. In the Isotonic Solutions and Major Adverse Renal Events Trial (SMART) in ICU and non-ICU patients, a protective renal effect favoring the use of balanced solution with an absolute reduction in the risk of major adverse kidney events by 1.1 [1.092-1.107] \% for ICU patients and $0.9[0.889-0.911] \%$ for non-ICU patients $[53,54]$ was observed. However, it is important to note that the frailty index calculated for the SMART studies, which is a complementary means to the $\mathrm{p}$ value for the interpretation of the results of the clinical trials, was very low. This observation suggesting a low robustness of the results [55]. But frailty index can also be interpreted as the reflection of a consistent choice of the size of the population studied for the size of the effect observed. Finally, its use is recently debated because it has been proven to lack the ability of the frailty index to quantify deviations from a model's null assumptions [56]. While the case of balanced crystalloids vs normal saline is not closed, accumulating evidence strongly suggest that (1) normal saline is not superior to balanced solution and (2) balanced solution are likely to be superior to normal saline in acutely and critically ill patient. Pending ongoing trials, this justifies in our view the use of balanced solutions as first line fluids in ICU patients.

Besides the choice of solute, the concept of the optimal mean arterial pressure target has been advocated for a long time. In the EPI-AKI study, factors associated with AKI included a past medical history of hypertension or shock at ICU admission, with higher ssimplified acute

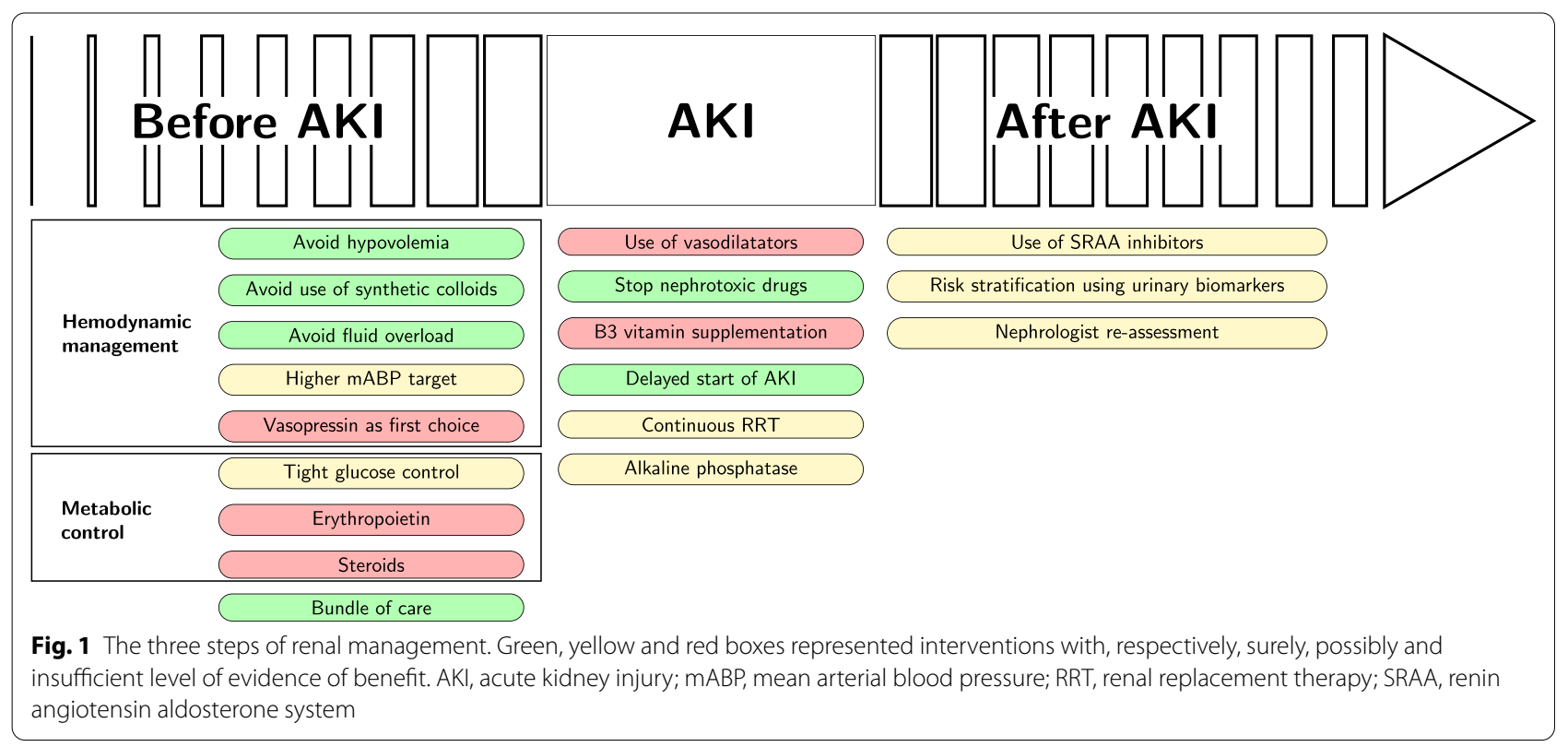


physiology score 3 [8]. These results are in line with those of the SEPSIS-PAM trial [57]. SEPSIS-PAM was a randomized controlled trial (RCT) targeting a mean arterial pressure of either 65 or $85 \mathrm{mmHg}$. It evidenced a significantly lower proportion of severe AKI and rate of renal replacement therapy in patients with chronic hypertension in the higher blood pressure group (31 vs. $42 \%$, $p=0.04$ ) [57]. This relationship had been demonstrated in physiological studies which strongly suggested that glomerular filtration rate (GFR) and RBF can vary widely across mean arterial pressure (mABP) ranges, but, however, the impact of raising $\mathrm{mABP}$ on renal hemodynamic varies on an individual basis [58]. In the 65 trial, a strategy of permissive hypotension strategy vs. usual care in patients aged 65 years or older and admitted to ICU for vasodilatory hypotension was tested. No difference was observed with respect to the incidence of RRT, including among the subgroup of patient with a history of hypertension [59]. However, such a lack of difference should be interpreted with caution due to the small difference of $\mathrm{mABP}$ levels between groups (respectively mABP of 67 [64-70] mmHg and mABP of 73 [69-76] $\mathrm{mmHg}$ ). In another ICU population, renal adverse events were less frequently observed in the high target patients (4 vs. $9 \%, p=0.002)$ in an RCT including patients admitted to the ICU for acute intracerebral hemorrhage [60]. Taken together, these findings do not support yet a wide use of higher mABP targets in patients with shock to protect the kidney. However, physiological studies strongly suggest that glomerular filtration rate and renal blood flow can vary widely across $\mathrm{mABP}$ ranges and the impact of raising $\mathrm{mABP}$ on renal hemodynamic varies on an individual basis [58].

During shock, it has been well demonstrated that a decrease in blood pressure below the limit of renal selfregulatory capacity lead to an almost linear drop in RBF. While norepinephrine remains the first-choice vasopressor to maintain arterial perfusion, its direct effects on $\mathrm{RBF}$ remains controversial. On one hand, norepinephrine has been shown to decrease RBF in healthy volunteers and its nephrotoxic impact is frequently used in fundamental research on animal models to promote AKI [61, 62]. On the other hand, in distributive shock, the use of norepinephrine restores RBF [58, 63]. Vasopressin has been suggested to improve renal outcomes in preliminary reports. However, vasopressin has not yet been shown superior to norepinephrine in preventing AKI in ICU patients [64-66].

\section{Improve the oxygen supply/need balance}

Numerous other procedures aiming to improve intrarenal perfusion or oxygenation have been evaluated, including renal vasodilators, control of renal hypercatabolism, anti-inflammatory, and antioxidants drugs. Among them, dopamine is undoubtedly the most extensively studied one. Its administration at low doses $(<5 \mu \mathrm{g} / \mathrm{kg} / \mathrm{min})$ inducing special in dopaminergic and $\beta$-adrenergic effect and therefore causes renal vasodilatation. However, despite intensive research for more than 30 years, date remain largely inconclusive to prevent occurrence of AKI [67]. Other vasodilators agents, like fenoldopam, B-type natriuretic peptide, and levosimendan, have failed to show any renal benefit [68-71]. Erythropoietin, steroids, tight glucose control, and numerous metabolic interventions have also been used to prevent kidney damage in various conditions. Except for the control of blood glucose level for which conflicting results have been obtained [72, 73], no renal benefit has been observed with these metabolic interventions as well [74-76].

\section{Bundles}

Beyond a single intervention, "bundles" have been proposed to prevent AKI [77, 78]. Bundles are a small, straightforward set of evidence-based practices that have been proven to improve patient outcomes when performed collectively and reliably (Fig. 2). This seems to allow better recognition [79] and reduce the risk of AKI progression [80]. Implementation of bundles has been able to demonstrate a reduction in the incidence of AKI in specific settings such as nephrotoxic AKI or post-cardiac surgery $[81,82]$. Whether implementing those bundles in general ICU population or in sepsis could prevent AKI is still unknown.

\section{During the AKI: improving early recovery from AKI Activation of the PGC1a-NAD pathway}

While no specific treatment of AKI is yet available, numerous advances in the understanding of the mechanisms leading to AKI in ischemic or septic conditions have been made over the last years. Among them, the PPAR Gamma Coactivator 1 alpha Nicotinamide Adenine Dinucleotide (PGC1 $\alpha$-NAD) pathway is one of the most promising targets for AKI. As renal proximal tubular cells are one of the most energy or ATP demanding cells in the body, they are very dependent on mitochondrial function. An increase in the expression of PGC1 $\alpha$ in renal epithelial cells subjected to ischemic stress was found protective, with a rise of NAD $+[83,84]$. Furthermore, decrease expression of PGC1 $\alpha$ was observed on human kidney biopsies in patients with AKI [84]. PPAR agonists have been proposed to prevent AKI induced by cisplatin or ischemia-reperfusion [85, 86]. The first class tested was fibrates, with mixed results $[85,86]$. Another approach was to increase the oxidation of fatty acid (AF) by improving the transport of AF in the mitochondrial 


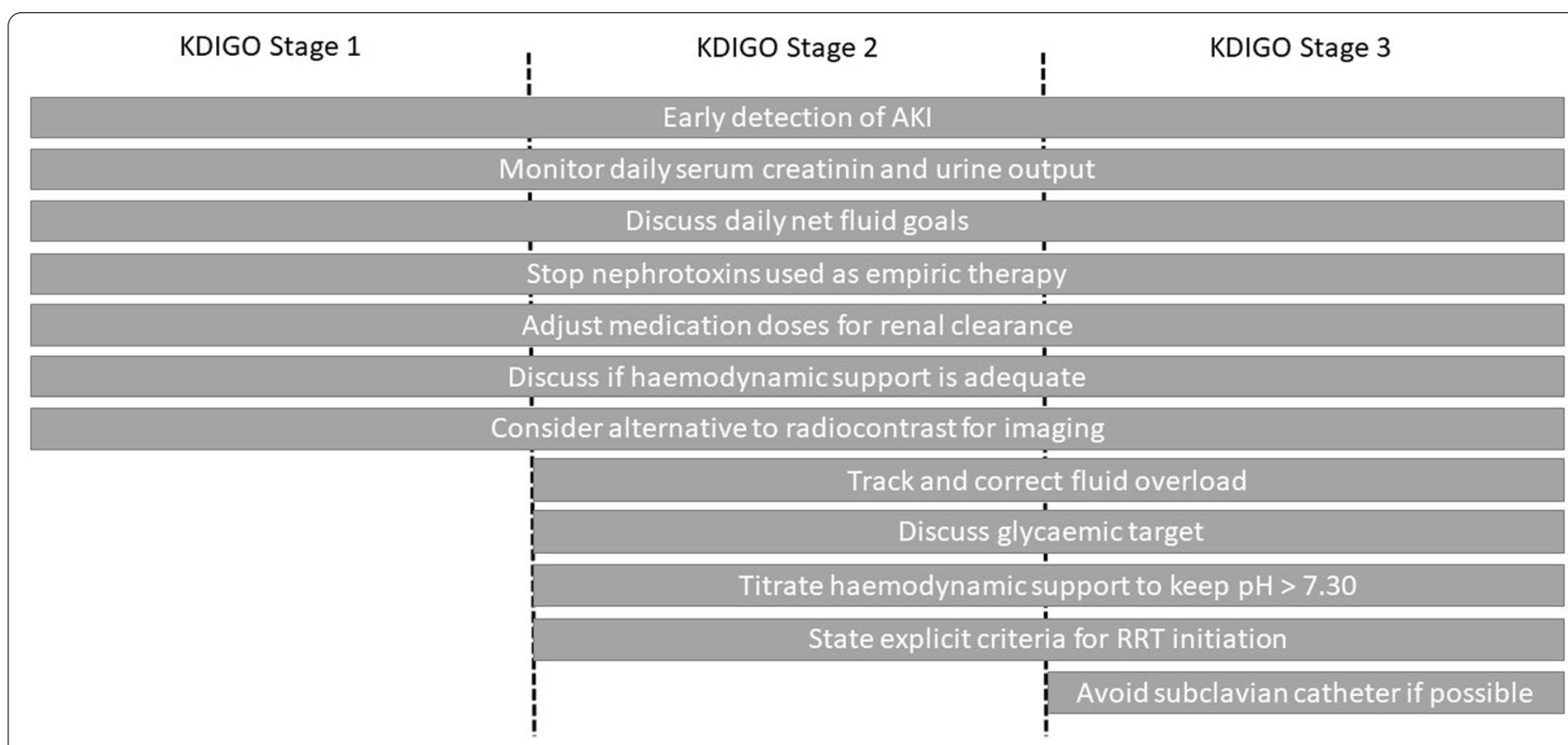

Fig. 2 Acute kidney injury bundles of care (derived from the KDIGO AKI management guidelines). Grey boxes indicate action to establish according to KDIGO severity stages. AKI, acute kidney injury; RRT, renal replacement therapy

matrix using association with carnitine and an activator of the carnitine palmitoyl-transferase 1 also called enzyme of the carnitine shuttle [87]. However, these are essentially preclinical data with no evaluation in patients. Nicotinamide (Nam), the amine form of Vitamin B3 (niacin), was identified as a potential stimulator of the production of NAD + [88]. After promising preclinical experiments, the administration of Nam was evaluated in the prevention of postoperative AKI in cardiac surgery in a single center trial with encouraging results [89]. In this phase 1 pilot study, 37 patients after cardiac surgery were randomly assigned in three groups: placebo, nicotinamide $1 \mathrm{~g}$ per day and $3 \mathrm{~g}$ per day. The areas under the curve of all longitudinal SCr measured after randomization were higher in placebo group vs patients received nicotinamide supplementation. While these results deserve to be reassessed in larger samples with more suitable outcome, emerging data linking the NAD + equilibrium to AKI resistance opens a new exciting chapter in AKI research $[88,90]$.

\section{Renal replacement therapy: the right time to the right patient}

The modality and the timing of initiation of RRT impact renal outcome. Concerning the modalities, it has been historically suggested that continuous techniques is associated with better hemodynamic stability [91]. Continuous RRT (CRRT) appear to result into fewer hypotension episodes during RRT sessions, allowing better renal perfusion, and, therefore, better recovery of renal function
[92], potentially due to lower ultrafiltration rate and lower osmotic shifts compared to IHD [93]. After identifying 6,627 patients treated by RRT in ICU and survivors at day 90 , Wald et al. were able to compare 2,004 patients treated with CRRT with 2,004 patients treated with intermittent hemodialysis (IHD) using a propensity score matching. Patients treated with IHD vs. CRRT were at higher risk of ESRD at 90 days (8.2 per 100 patientyears vs. 6.5 per 100 patient-year; $\mathrm{HR}=0.75$ [0.65-0.87]) [94]. However, these results were not confirmed in a subsequent study, which included 638 patients admitted to a single tertiary care academic medical center for 8 years and treated with RRT. After applying a conditional logistic regression model stratified by propensity score for CRRT, there was no significant higher risk of dialysis dependence at day $90(\mathrm{OR}=1.19[0.91-1.55]$ for CRRT, $p=0.20)$ and day $365(\mathrm{OR}=0.93[0.72-1.20]$ for CRRT, $p=0.55$ ). Even if a difference favoring CRRT at day 90 was observed (186/244 (76.2\%) for CRRT patients vs. $66 / 101(65.3 \%)$ for IHD patients, $p=0.05)$, this association did not remain significant at day 365 [95]. Exploration of the French electronic health record revealed an association between the use of IHD and the risk of developing CKD among ICU patients [96]. The KDIGO guidelines suggest the use of CRRT for patients with unstable hemodynamics but with moderate level of evidence [7], since available RCTs were not designed to address the impact on renal outcome [97]. While the timing of renal replacement therapy does not affect survival in critically ill patients [98-102], data suggest potential 
harm of a liberal use of RRT on renal recovery. No difference in renal recovery was observed at day 90 in both the ELAIN study (9/67 (13.4\%) for the early group vs. 8/53 (15.1\%) for the delayed group, $p=0.80)$ and the IDEALICU trial $(2 / 101$ (2\%) for the early group vs. $3 / 110(3 \%)$ for the delayed group, $p>0.90$ ) [99, 102]. Recently, a higher RRT dependence among survivors at day 90 was observed in the STARRT-AKI study (85/814 (10.4\%) for the accelerated group vs. $49 / 815(6.0 \%)$ for the standard group). Concerning long-term outcome, analysis from the extended 1 year follow-up of the ELAIN study suggested better prognosis of early initiation of RRT whether in terms of mortality (absolute difference $-19.6(-32$; $-7.2) \%, p<0.01$ ) or recover of renal function (absolute difference $=-34.8(-54.6 ;-15) \%, p=0.001)$ [103].

\section{After AKI: Preventing the long-term consequences The maladaptive repair concept and the evolution to the renal fibrosis}

For a long time, the suspected renal lesion of AKI was acute tubular necrosis (ATN), otherwise described as transient with full recovery. It is now well established that that the repair after ATN is ultimately imperfect, culminating in the concept of "maladaptive repair." This "maladaptive repair" initiates fibrogenesis even when morphology and renal function have apparently returned to normal. Similarly, increasing evidence in kidney transplants suggests that ischemic episodes are connected to transplant fibrosis [104]. So far, four significant pathways have been identified to trigger fibrosis after an episode of transient AKI: (a) the epigenetic silencing of RASAL1, a proliferation inhibitor, in myofibroblasts; (b) the cell cycle arrest in G2/M in tubular epithelial cells (the G2/M phase is where the epithelial cell function is closer to a mesenchymal one); (c) down-regulation of FA oxydatoin in tubular epithelial cells [105-107]; and the activation of the renin-angiotensin-aldosterone system (SRAA) [108-110].

\section{Blocking the renin-angiotensin system to prevent fibrinogenesis}

Activation of the SRAA is a key pathway for the development of chronic cardiovascular disease.

Angiotensin II (AngII) has been shown to induce cytokine secretion by tubular cells and promoting the accumulation of inflammatory cells in both the tubular and glomerular compartments [108]. The MD2/TLR4/ MyD88 plays a pivotal role in mediating the proinflammatory effects of AngII [109]. Further damage to the kidney may arise from the activation of the coagulation cascade and leucocyte adhesion in microvessels [111]. Reciprocally, antagonization of AngII confers renal protection in a model of subtotal nephrectomy in rats
[110]. Unsurprisingly, AngII has been widely utilized to enhance the onset of renal injury in animal models. Additionally, robust data suggest that AngII is a crucial contributor to the progression of renal fibrosis and chronic kidney disease via tissue inflammation and matrix protein deposition [109]. Conversely, some experimental work has suggested a deficit in SRAA activity, contributing to vasoplegia during distributive shock [112]. AngII has been investigated to restore the arterial pressure in patients on high doses of vasopressors in a recent RCT [113]. However, the long-term assessment, in particular concerning the occurrence of CKD in survivors, has not yet been carried out, particularly in patients treated for an extended period of time [114].

On the other hand, several observational data suggest a beneficial effect of blocking the SRAA in patients recovering from AKI. In a cohort of 611 patients with AKI during ICU stay and discharged alive from ICU, the presence of SRAA inhibitor at ICU discharged was associated with lower mortality with a propensity score-matched hazard ratio of 0.48 [0.27-0.85], $p<0.01$ ) [115]. Similar results were observed in another large Canadian cohort, including 46,253 patients who suffered AKI during hospitalization. Blocking SRAA was associated with better outcomes at 2 years $(\mathrm{HR}=0.85[0.81-0.89], p<0.01)$ but was not associated with ESRD or composite outcome composed by ESRD or sustained doubling of serum creatinine [116]. These results were not observed in an ancillary study of the AKIKI trial, which failed to evidence any beneficial association between SRAA blockers and 2-years outcomes in KDIGO3 survivors [117]. Of note, this study was likely to lack power. No increased risk of recurrent hospitalized AKI was observed after the new use of SRAA blockers suggesting that starting or resuming these medications is safe after AKI $[118,119]$.

\section{Follow-up}

While the reassessment of patients 3 months after AKI is highly recommended by KDIGO guidelines [7], several studies have highlighted the fact that only a small proportion of patients ultimately benefit from this reassessment. Available data show that less than $30 \%$ of patients who suffered AKI during hospitalization are reassessed within the first year after discharge, including patients with CKD or pre-existing diabetes $[120,121]$, despite the current recommendation by nephrologists [122]. However, such a follow-up seems to impact the outcome through the optimization of treatments, detection, and prevention of cardiovascular diseases and prevention of new episodes of AKI. In an Ontario population-based cohort study, 3,877 patients who suffered AKI treated by renal replacement therapy and discharged alive from the hospital were evaluated depending on the completion of a 
follow-up consultation [123]. A visit with a nephrologist within 90 days after discharge was associated with a $24 \%$ decrease in mortality after 2 years of follow-up. However, with the increase in hospitalization rates complicated by AKI, the general application of reassessment may exceed existing capacity of nephrology programs. Given the poor outcome of AKI survivors, RCT and prospective observational studies, as the ongoing French PREDICT multicenter study [124], are needed to determine which subpopulations of patients would benefit most from these interventions.

\section{Perspectives on AKI research: an incredible playground in terms of epidemiology, basic science, and translational research}

In recent years, due to the generalization of big databases, artificial intelligence (AI) techniques have been increasingly crucial in critical care. AKI is not exempt from the application of AI techniques, in particular, to predict AKI occurrence or aggravation [125-129]. A deep learning model developed on electronic health records from 703,782 adult patients could predict $55.8 \%$ of all episodes of AKI, $90.2 \%$ of all AKI required dialysis, with a lead time of up to $48 \mathrm{~h}$ and a ratio of 2 false alerts for every real alert [125]. However, the major limitation of these models is that the prediction of AKI is derived from variations in $\mathrm{SCr}$, which remains an imperfect marker for renal function [130].

To date, the search for new biological (plasmatic or urinary NGAL, KIM-1, Cystatin C, TIMP-2, IGFBP7) or non-biological (intra-renal Doppler flow indices) marker of kidney injury represent an essential part of the literature with contradictory results. Rather than helping in the diagnosis of AKI, they can be useful in predicting the most severe forms of AKI [131] or detect kidney injury in patients not meeting the current definition of AKI (i.e. so-called sub-clinical AKI). If both RCTs AKIKI and IDEAL-ICU did not demonstrate any survival benefit according to the time to onset of RRT for all patients with stage $3 \mathrm{AKI}$, the high mortality rate observed in patients who underwent RRT later justifies the need to identify persistent AKI $[98,99]$. In a multicenter international prospective observation study, Hoste et al. had identified for the first time a new urinary biomarker, the $\mathrm{C}-\mathrm{C}$ motif chemokine ligand $14\left(\mathrm{CCL}_{14}\right)$, with good discrimination (AUC $=0.83$ [0.78-0.87]) [132]. If the discovery of $\mathrm{CCL}_{14}$ as a predictor of persistent $\mathrm{AKI}$ is not the first one to suggest the role of monocytes/macrophages in the pathophysiology of AKI, especially in sepsis [133], it offers the opportunity to identify new approaches of AKI therapy. Moreover, the promise of early intervention able to improve renal outcome in infraclinic AKI must be encouraged by the development of biomarkers research.

The impact of strategies of RRT on renal recovery remains poorly understood and should be explored. Finally, strategies to prevent long-term development of both chronic and cardiovascular diseases require full attention to limits the AKI "scar".

Finally, behind therapeutic innovations, next years will bring out new endpoints that will allow us to better define endpoints of interest in the setting of AKI (Table 1), better report the prevalence of AKI/CKD/ESRD and overall survival, and improve our tools to measure actual realtime GFR, functional renal reserve and kidney damage.

\section{Conclusion}

AKI is highly prevalent among ICU patients and has been associated with short- and long-term outcomes. Several therapeutic strategies can either prevent or mitigate the consequences of AKI. Future research should now identify sub-phenotypes of AKI with different response to available treatments, tools for earlier and better recognition of kidney damage and renal function and innovative

Table 1 Classical and potential endpoint used to evaluate efficacy of AKI procedure

\begin{tabular}{lll}
\hline & Classical outcome & Potential outcome \\
\hline Prevention & AKl prevalence & Real time GFR \\
Clinical management & Change of biomarker & Time free of RRT \\
& ICU death & AKI as competitive event to \\
& Dialysis dependency at discharge & death/complicatoin \\
Follow-up & & Recovery of renal function \\
& & Functional renal reserve \\
& Long-term survival & Measure of GFR \\
& End-stage kidney disease & Patient-related quality of life
\end{tabular}




\section{therapeutic strategies with the ultimate goal of improving patient-centered outcomes.}

\begin{abstract}
Abbreviations
AKI: Acute kidney injury; ICU: Intensive care unit; CKD: Chronic kidney disease; RRT: Renal replacement therapy; ESRD: End-stage renal disease; ACR: Albumine-to-creatinine ratio; RBF: Renal blood flow; mABP: Mean arterial blood pressure; GFR: Glomerular filtration rate; RCT: Randomized control trial; PGC1 aNAD: PPAR gamma coactivator 1 alpha nicotinamide adenine dinucleotide; FA: Fatty acid; CRRT: Continuous renal replacement therapy; IHD: Intermittent hemodialysis; ATN: Acute tubular necrosis; SRAA: Renin-angiotensin-aldosterone system; Angll: Angiotensin II; $\mathrm{CCL}_{14}: \mathrm{C}-\mathrm{C}$ motif chemokine ligand 14.
\end{abstract}

\section{Acknowledgements}

None.

\section{Author contributions}

MJ performed review of the literature. MJ, ML and GG wrote the manuscript. MJ designed figure. All authors read and approved the final manuscript.

\section{Funding}

None.

\section{Availability of data and materials}

Not applicable.

\section{Declarations}

\section{Ethics approval and consent to participate}

Not applicable.

\section{Consent for publication}

Not applicable.

\section{Competing interests}

Dr Jamme reports lectures fees from Alexion. Pr Legrand reports lecture fees from Baxter and Fresenius, consulting fees from Novartis and research support from Sphingotec. Pr Geri reports accomodation fees from BD-Bard.

\section{Author details}

1 Service de Réanimation, Hôpital de Poissy, CHI Poissy Saint Germain, 10 rue du champ Gaillard, 78300 Poissy, France. ${ }^{2}$ INSERM UMR 1018, Equipe Epidémiologie clinique, CESP, Villejuif, France. ${ }^{3}$ Université Paris Saclay, UFR Simone Veil - Santé, Montigny-Le-Bretonneux, France. ${ }^{4}$ Department of Anesthesia and Perioperative Care, University of California, San Francisco, USA. ${ }^{5}$ Service de Médecine Intensive Réanimation, Hôpital Ambroise Paré, AP-HP, Boulogne Billancourt, France.

Received: 30 July 2020 Accepted: 3 April 2021

Published online: 15 April 2021

\section{References}

1. Smith HW. The kidney: structure and function in health and disease. New York: Oxford University Press; 1951.

2. Kellum JA, Levin N, Bouman C, Lameire N. Developing a consensus classification system for acute renal failure. Curr Opin Crit Care. 2002;8(6):509-14.

3. Uchino S, Kellum JA, Bellomo R, et al. Acute renal failure in critically ill patients: a multinational, multicenter study. JAMA. 2005;294(7):813-8.

4. de Mendonça A, Vincent JL, Suter PM, Moreno R, Dearden NM, Antonelli $\mathrm{M}$, et al. Acute renal failure in the ICU: risk factors and outcome evaluated by the SOFA score. Intensive Care Med. 2000;26(7):915-21.

5. Bellomo R, Ronco C, Kellum JA, Mehta RL, Palevsky P, Acute Dialysis Quality Initiative workgroup. Acute renal failure-definition, outcome measures, animal models, fluid therapy and information technology needs: the Second International Consensus Conference of the
Acute Dialysis Quality Initiative (ADQI) Group. Crit Care Lond Engl. 2004;8(4):R204-212.

6. Mehta RL, Kellum JA, Shah SV, Molitoris BA, Ronco C, Warnock DG, et al. Acute Kidney Injury Network: report of an initiative to improve outcomes in acute kidney injury. Crit Care. 2007;11(2):R31.

7. KDIGO AKI Workgorup. KDIGO clinical practice guideline for acute kidney injury. Kidney Int Suppl. 2012;2(1):1

8. Hoste EAJ, Bagshaw SM, Bellomo R, Cely CM, Colman R, Cruz DN, et al. Epidemiology of acute kidney injury in critically ill patients: the multinational AKI-EPI study. Intensive Care Med. 2015;41(8):1411-23.

9. Fuhrman DY, Kane-Gill S, Goldstein SL, Priyanka P, Kellum JA. Acute kidney injury epidemiology, risk factors, and outcomes in critically ill patients $16-25$ years of age treated in an adult intensive care unit. Ann Intensive Care. 2018;8(1):26.

10. du Cheyron D, Bouchet B, Parienti J-J, Ramakers M, Charbonneau P. The attributable mortality of acute renal failure in critically ill patients with liver cirrhosis. Intensive Care Med. 2005;31 (12):1693-9.

11. Honore PM, Jacobs R, Joannes-Boyau O, De Regt J, Boer W, De Waele E, et al. Septic AKI in ICU patients. Diagnosis, pathophysiology, and treatment type, dosing, and timing: a comprehensive review of recent and future developments. Ann Intensive Care. 2011;1(1):32.

12. Gameiro J, Fonseca JA, Neves M, Jorge S, Lopes JA. Acute kidney injury in major abdominal surgery: incidence, risk factors, pathogenesis and outcomes. Ann Intensive Care. 2018:8(1):22.

13. Drolz A, Horvatits T, Roedl K, Rutter K, Staufer K, Haider DG, et al. Outcome and features of acute kidney injury complicating hypoxic hepatitis at the medical intensive care unit. Ann Intensive Care. 2016;6(1):61.

14. Panitchote A, Mehkri O, Hastings A, Hanane T, Demirjian S, Torbic H, et al. Factors associated with acute kidney injury in acute respiratory distress syndrome. Ann Intensive Care. 2019;9(1):74.

15. Darmon M, Vincent F, Canet E, Mokart D, Pène F, Kouatchet A, et al. Acute kidney injury in critically ill patients with haematological malignancies: results of a multicentre cohort study from the Groupe de Recherche en Réanimation Respiratoire en Onco-Hématologie. Nephrol Dial Transplant Off Publ Eur Dial Transpl Assoc Eur Ren Assoc. 2015;30(12):2006-13.

16. Dépret F, Hollinger A, Cariou A, Deye N, Vieillard-Baron A, Fournier M-C, et al. Incidence and outcome of sub-clinical acute kidney injury using penKid in critically III patients. Am J Respir Crit Care Med. 2020. https:// doi.org/10.1164/rccm.201910-19500C

17. Mildh H, Pettilä V, Korhonen A-M, Karlsson S, Ala-Kokko T, Reinikainen M, et al. Three-year mortality in 30-day survivors of critical care with acute kidney injury: data from the prospective observational FINNAKI study. Ann Intensive Care. 2016;6(1):118.

18. Kellum JA, Sileanu FE, Bihorac A, Hoste EAJ, Chawla LS. Recovery after Acute Kidney Injury. Am J Respir Crit Care Med. 2016:195(6):784-91.

19. Legrand M, Hollinger A, Vieillard-Baron A, Dépret F, Cariou A, Deye N, et al. One-year prognosis of kidney injury at discharge from the ICU: a multicenter observational study. Crit Care Med. 2019:47(12):e953-61.

20. Wald R, Quinn RR, Luo J, Li P, Scales DC, Mamdani MM, et al. Chronic dialysis and death among survivors of acute kidney injury requiring dialysis. JAMA. 2009;302(11):1179-85.

21. Rimes-Stigare C, Frumento P, Bottai M, Mårtensson J, Martling C-R, Walther SM, et al. Evolution of chronic renal impairment and long-term mortality after de novo acute kidney injury in the critically ill; a Swedish multi-centre cohort study. Crit Care Lond Engl. 2015;6(19):221.

22. Rimes-Stigare C, Frumento P, Bottai M, Mårtensson J, Martling C-R, Bell M. Long-term mortality and risk factors for development of end-stage renal disease in critically ill patients with and without chronic kidney disease. Crit Care. 2015;19(1):383.

23. Ishani A, Xue JL, Himmelfarb J, Eggers PW, Kimmel PL, Molitoris BA, et al. Acute kidney injury increases risk of ESRD among elderly. J Am Soc Nephrol JASN. 2009;20(1):223-8.

24. Greenberg JH, Coca S, Parikh CR. Long-term risk of chronic kidney disease and mortality in children after acute kidney injury: a systematic review. BMC Nephrol. 2014;21(15):184.

25. Thakar CV, Christianson A, Himmelfarb J, Leonard AC. Acute kidney injury episodes and chronic kidney disease risk in diabetes mellitus. Clin J Am Soc Nephrol CJASN. 2011;6(11):2567-72.

26. Legouis $D$, Galichon $P$, Bataille $A$, Chevret $S$, Provenchère $S$, Boutten A, et al. Rapid occurrence of chronic kidney disease in patients 
experiencing reversible acute kidney injury after cardiac surgery. Anesthesiology. 2017;126(1):39-46.

27. Jamme M, Ait Hamou Z, Ben Hadj Salem O, Guillemet L, Bougouin $W$, Pène $F$, et al. Long term renal recovery in survivors after OHCA. Resuscitation. 2019;141:144-50.

28. Hsu C, Chinchilli VM, Coca S, Devarajan P, Ghahramani N, Go AS, et al. Post-acute kidney injury proteinuria and subsequent kidney disease progression: the assessment, serial evaluation, and subsequent sequelae in acute kidney injury (ASSESS-AKI) Study. JAMA Intern Med. 2020;180(3):402-10.

29. Chawla LS, Eggers PW, Star RA, Kimmel PL. Acute kidney injury and chronic kidney disease as interconnected syndromes. N Engl J Med. 2014:371(1):58-66.

30. Venkatachalam MA, Griffin KA, Lan R, Geng H, Saikumar P, Bidani AK. Acute kidney injury: a springboard for progression in chronic kidney disease. Am J Physiol Renal Physiol. 2010;298(5):F1078-1094.

31. Shirakabe A, Hata N, Kobayashi N, Shinada T, Tomita K, Tsurumi M, et al. Long-term prognostic impact after acute kidney injury in patients with acute heart failure. Int Heart J. 2012;53(5):313-9.

32. James MT, Ghali WA, Knudtson ML, Ravani P, Tonelli M, Faris P, et al. Associations between acute kidney injury and cardiovascular and renal outcomes after coronary angiography. Circulation. 2011;123(4):409-16.

33. Wu V-C, Wu C-H, Huang T-M, Wang C-Y, Lai C-F, Shiao C-C, et al. Long-term risk of coronary events after AKI. J Am Soc Nephrol JASN. 2014;25(3):595-605.

34. Odutayo A, Wong CX, Farkouh M, Altman DG, Hopewell S, Emdin CA, et al. AKI and long-term risk for cardiovascular events and mortality. J Am Soc Nephrol JASN. 2017;28(1):377-87.

35. Go AS, Hsu C-Y, Yang J, Tan TC, Zheng S, Ordonez JD, et al. Acute kidney injury and risk of heart failure and atherosclerotic events. Clin J Am Soc Nephrol CJASN. 2018;13(6):833-41.

36. Sumida M, Doi K, Ogasawara E, Yamashita T, Hamasaki Y, Kariya T, et al. Regulation of mitochondrial dynamics by dynamin-related protein-1 in acute cardiorenal syndrome. J Am Soc Nephrol. 2015;26(10):2378-87.

37. Parikh CR, Puthumana J, Shlipak MG, Koyner JL, Thiessen-Philbrook H, McArthur E, et al. Relationship of kidney injury biomarkers with longterm cardiovascular outcomes after cardiac surgery. J Am Soc Nephrol. 2017;28(12):3699-707.

38. Legrand M, Rossignol P. Cardiovascular consequences of acute kidney injury. N Engl J Med. 2020. https://doi.org/10.1056/NEJMra1916393.

39. Prud'homme M, Coutrot M, Michel T, Boutin L, Genest M, Poirier F, et al. Acute kidney injury induces remote cardiac damage and dysfunction through the galectin-3 pathway. JACC Basic TransI Sci. 2019;4(6):717-32.

40. Silvester W, Bellomo R, Cole L. Epidemiology, management, and outcome of severe acute renal failure of critical illness in Australia. Crit Care Med. 2001;29(10):1910-5.

41. Moman RN, Ostby SA, Akhoundi A, Kashyap R, Kashani K. Impact of individualized target mean arterial pressure for septic shock resuscitation on the incidence of acute kidney injury: a retrospective cohort study. Ann Intensive Care. 2018;8(1):124.

42. Payen D, de Pont AC, Sakr Y, Spies C, Reinhart K, Vincent JL, et al. A positive fluid balance is associated with a worse outcome in patients with acute renal failure. Crit Care Lond Engl. 2008;12(3):R74.

43. Vincent J-L, Sakr Y, Sprung CL, Ranieri VM, Reinhart K, Gerlach H, et al. Sepsis in European intensive care units: results of the SOAP study. Crit Care Med. 2006;34(2):344-53.

44. Rozich JD, Paul RV. Acute renal failure precipitated by elevated colloid osmotic pressure. Am J Med. 1989:87(3):358-60.

45. Legendre C, Thervet E, Page B, Percheron A, Noël LH, Kreis H. Hydroxyethylstarch and osmotic-nephrosis- like lesions in kidney transplantation. The Lancet. 1993;342(8865):248-9.

46. Futier E, Garot M, Godet T, Biais M, Verzilli D, Ouattara A, et al. Effect of hydroxyethyl starch vs saline for volume replacement therapy on death or postoperative complications among high-risk patients undergoing major abdominal surgery: the FLASH randomized clinical trial. JAMA. 2020:323(3):225-36.

47. Myburgh JA, Finfer S, Bellomo R, Billot L, Cass A, Gattas D, et al. Hydroxyethyl starch or saline for fluid resuscitation in intensive care. N Engl J Med. 2012;367(20):1901-11.
48. Perner A, Haase N, Guttormsen AB, Tenhunen J, Klemenzson G, Åneman A, et al. Hydroxyethyl starch 130/0.42 versus ringer's acetate in severe sepsis. N Engl J Med. 2012;367(2):124-34.

49. Yunos NM, Bellomo R, Hegarty C, Story D, Ho L, Bailey M. Association between a chloride-liberal vs chloride-restrictive intravenous fluid administration strategy and kidney injury in critically III adults. JAMA. 2012;308(15):1566-72.

50. Shaw AD, Raghunathan K, Peyerl FW, Munson SH, Paluszkiewicz SM, Schermer CR. Association between intravenous chloride load during resuscitation and in-hospital mortality among patients with SIRS. Intensive Care Med. 2014;40(12):1897-905.

51. Williams EL, Hildebrand KL, McCormick SA, Bedel MJ. The effect of intravenous lactated Ringer's solution versus $0.9 \%$ sodium chloride solution on serum osmolality in human volunteers. Anesth Analg. 1999;88(5):999-1003.

52. Young P, Bailey M, Beasley R, Henderson S, Mackle D, McArthur C, et al. Effect of a buffered crystalloid solution vs saline on acute kidney injury among patients in the intensive care unit: the SPLIT Randomized Clinical Trial. JAMA. 2015;314(16):1701-10.

53. Semler MW, Wanderer JP, Ehrenfeld JM, Stollings JL, SelfWH, Siew ED, et al. Balanced crystalloids versus saline in the intensive care unit. The SALT Randomized Trial. Am J Respir Crit Care Med. 2016;195(10):1362-72.

54. Self WH, Semler MW, Wanderer JP, Wang L, Byrne DW, Collins SP, et al. Balanced crystalloids versus saline in noncritically III adults. N Engl J Med. 2018;378(9):819-28.

55. Ridgeon EE, Young PJ, Bellomo R, Mucchetti M, Lembo R, Landoni G. The fragility index in multicenter randomized controlled critical care trials. Crit Care Med. 2016;44(7):1278-84.

56. Potter GE. Dismantling the fragility index: a demonstration of statistical reasoning. Stat Med. 2020;39:3720-31.

57. Asfar P, Meziani F, Hamel J-F, Grelon F, Megarbane B, Anguel N, et al. High versus low blood-pressure target in patients with septic shock. N Engl J Med. 2014;370(17):1583-93.

58. Redfors B, Bragadottir G, Sellgren J, Swärd K, Ricksten S-E. Effects of norepinephrine on renal perfusion, filtration and oxygenation in vasodilatory shock and acute kidney injury. Intensive Care Med. 2011;37(1):60-7.

59. Lamontagne F, Richards-Belle A, Thomas K, Harrison DA, Sadique MZ, Grieve RD, et al. Effect of reduced exposure to vasopressors on 90-day mortality in older critically III patients with vasodilatory hypotension: a randomized clinical trial. JAMA. 2020;323(10):938-49.

60. Qureshi Al, Palesch YY, Barsan WG, Hanley DF, Hsu CY, Martin RL, et al. Intensive blood-pressure lowering in patients with acute cerebral hemorrhage. N Engl J Med. 2016;375(11):1033-43.

61. Schrier RW, Arnold PE, Gordon JA, Burke TJ. Protection of mitochondrial function by mannitol in ischemic acute renal failure. Am J Physiol-Ren Physiol. 1984;247(2):F365-9.

62. Hoogenberg K, Smit AJ, Girbes ARJ. Effects of low-dose dopamine on renal and systemic hemodynamics during incremental norepinephrine infusion in healthy volunteers. Crit Care Med. 1998;26(2):260-5.

63. Bellomo R, Kellum JA, Wisniewski SR, Pinsky MR, Ondulik B. Effects of norepinephrine on the renal vasculature in normal and endotoxemic dogs. Am J Respir Crit Care Med. 1999;159(4):1 186-92.

64. Hajjar L, Vincent J, Galas FBG, Rhodes A, Landoni G, Osawa E, et al. Vasopressin versus norepinephrine in patients with vasoplegic shock after cardiac surgery: the VANCS Randomized Controlled Trial. Anesthesiology. 2017;126(1):85-93.

65. Gordon AC, Mason AJ, Thirunavukkarasu N, Perkins GD, Cecconi M, Cepkova $M$, et al. Effect of early vasopressin vs norepinephrine on kidney failure in patients with septic shock: the VANISH Randomized Clinical Trial. JAMA. 2016;316(5):509-18.

66. Russell JA, Walley KR, Singer J, Gordon AC, Hébert PC, Cooper DJ, et al. Vasopressin versus norepinephrine infusion in patients with septic shock. N Engl J Med. 2008;358(9):877-87.

67. Friedrich JO, Adhikari N, Herridge MS, Beyene J. Meta-analysis: low-dose dopamine increases urine output but does not prevent renal dysfunction or death. Ann Intern Med. 2005;142(7):510.

68. Bove T, Zangrillo A, Guarracino F, Alvaro G, Persi B, Maglioni E, et al. Effect of fenoldopam on use of renal replacement therapy among 
patients with acute kidney injury after cardiac surgery: a randomized clinical trial. JAMA. 2014;312(21):2244-53.

69. Gordon AC, Perkins GD, Singer M, McAuley DF, Orme RML, Santhakumaran $\mathrm{S}$, et al. Levosimendan for the prevention of acute organ dysfunction in sepsis. N Engl J Med. 2016;375(17):1638-48.

70. Landoni G, Lomivorotov W, Alvaro G, Lobreglio R, Pisano A, Guarracino F, et al. Levosimendan for hemodynamic support after cardiac surgery. N Engl J Med. 2017;376(21):2021-31.

71. Xiong B, Wang C, Yao Y, Huang Y, Tan J, Cao Y, et al. The dose-dependent effect of nesiritide on renal function in patients with acute decompensated heart failure: a systematic review and meta-analysis of randomized controlled trials. PLoS ONE. 2015;10(6):e0131326.

72. Schetz M, Vanhorebeek I, Wouters PJ, Wilmer A, Van den Berghe G. Tight blood glucose control is renoprotective in critically ill patients. J Am Soc Nephrol JASN. 2008;19(3):571-8

73. Ling Y, Li X, Gao X. Intensive versus conventional glucose control in critically ill patients: a meta-analysis of randomized controlled trials. Eur J Intern Med. 2012;23(6):564-74.

74. Guillemet L, Jamme M, Bougouin W, Geri G, Deye N, Vivien B, et al. Effects of early high-dose erythropoietin on acute kidney injury following cardiac arrest: exploratory post hoc analyses from an open-label randomized trial. Clin Kidney J. https://academic.oup.com/ckj/advancearticle/doi/https://doi.org/10.1093/ckj/sfz068/5519666. Accessed 21 Feb 2020.

75. Angstwurm MWA, Engelmann L, Zimmermann T, Lehmann C, Spes CH, Abel $P$, et al. Selenium in Intensive Care (SIC): Results of a prospective randomized, placebo-controlled, multiple-center study in patients with severe systemic inflammatory response syndrome, sepsis, and septic shock. Crit Care Med. 2007;35(1):118-26.

76. Whitlock RP, Devereaux PJ, Teoh KH, Lamy A, Vincent J, Pogue J, et al. Methylprednisolone in patients undergoing cardiopulmonary bypass (SIRS): a randomised, double-blind, placebo-controlled trial. Lancet Lond Engl. 2015;386(10000):1243-53.

77. Resar R, Pronovost P, Haraden C, Simmonds T, Rainey T, Nolan T. Using a bundle approach to improve ventilator care processes and reduce ventilator-associated pneumonia. Jt Comm J Qual Patient Saf. 2005;31(5):243-8

78. Bhagwanani A, Carpenter R, Yusuf A. Improving the management of Acute Kidney Injury in a District General Hospital: Introduction of the DONUT bundle. BMJ Open Qual. 2014;2(2). https://bmjopenquality.bmj. com/content/2/2/u202650.w1235. Accessed 1 Jan 2014.

79. Selby NM, Casula A, Lamming L, Stoves J, Samarasinghe Y, Lewington AJ, et al. An organizational-level program of intervention for AKl: a pragmatic stepped wedge cluster randomized trial. J Am Soc Nephrol. 2019;30(3):505-15.

80. Kolhe NV, Reilly T, Leung J, Fluck RJ, Swinscoe KE, Selby NM, et al. A simple care bundle for use in acute kidney injury: a propensity scorematched cohort study. Nephrol Dial Transplant. 2016;31(11):1846-54.

81. Goldstein SL, Dahale D, Kirkendall ES, Mottes T, Kaplan H, Muething S, et al. A prospective multi-center quality improvement initiative (NINJA) indicates a reduction in nephrotoxic acute kidney injury in hospitalized children. Kidney Int. 2020;97(3):580-8.

82. Meersch M, Schmidt C, Hoffmeier A, Van Aken H, Wempe C, Gerss J, et al. Prevention of cardiac surgery-associated AKI by implementing the KDIGO guidelines in high risk patients identified by biomarkers: the PrevAKI randomized controlled trial. Intensive Care Med. 2017:43(11):1551-61.

83. Li S, Nagothu KK, Desai V, Lee T, Branham W, Moland C, et al. Transgenic expression of proximal tubule peroxisome proliferator-activated receptor-alpha in mice confers protection during acute kidney injury. Kidney Int. 2009;76(10):1049-62.

84. Tran MT, Zsengeller ZK, Berg AH, Khankin EV, Bhasin MK, Kim W, et al. PGC1a-dependent NAD biosynthesis links oxidative metabolism to renal protection. Nature. 2016;531(7595):528-32.

85. Nagothu KK, Bhatt R, Kaushal GP, Portilla D. Fibrate prevents cisplatininduced proximal tubule cell death. Kidney Int. 2005:68(6):2680-93.

86. Takahashi K, Kamijo Y, Hora K, Hashimoto K, Higuchi M, Nakajima T, et al. Pretreatment by low-dose fibrates protects against acute free fatty acid-induced renal tubule toxicity by counteracting PPARa deterioration. Toxicol Appl Pharmacol. 2011;252(3):237-49.
87. Declèves A-E, Zolkipli Z, Satriano J, Wang L, Nakayama T, Rogac M, et al. Regulation of lipid accumulation by AMP-activated kinase [corrected] in high fat diet-induced kidney injury. Kidney Int. 2014;85(3):611-23.

88. Katsyuba E, Mottis A, Zietak M, De Franco F, van der Velpen V, Gariani K, et al. De novo NAD+ synthesis enhances mitochondrial function and improves health. Nature. 2018;563(7731):354-9.

89. Poyan Mehr A, Tran MT, Ralto KM, Leaf DE, Washco V, Messmer J, et al. De novo NAD+ biosynthetic impairment in acute kidney injury in humans. Nat Med. 2018;24(9):1351-9.

90. Guan Y, Wang S-R, Huang X-Z, Xie Q-H, Xu Y-Y, Shang D, et al. Nicotinamide mononucleotide, an NAD+ precursor, rescues age-associated susceptibility to AKI in a Sirtuin 1-dependent manner. J Am Soc Nephrol JASN. 2017;28(8):2337-52.

91. Rabindranath K, Adams J, Macleod AM, Muirhead N. Intermittent versus continuous renal replacement therapy for acute renal failure in adults. Cochrane Database Syst Rev. 2007:18(3):CD003773.

92. Clark WR, Mueller BA, Alaka KJ, Macias WL. A comparison of metabolic control by continuous and intermittent therapies in acute renal failure. J Am Soc Nephrol. 1994;4(7):1413-20.

93. Marants R, Qirjazi E, Grant CJ, Lee T-Y, McIntyre CW. Renal perfusion during hemodialysis: intradialytic blood flow decline and effects of dialysate cooling. J Am Soc Nephrol JASN. 2019;30(6):1086-95.

94. Wald R, Shariff SZ, Adhikari NKJ, Bagshaw SM, Burns KEA, Friedrich JO, et al. The association between renal replacement therapy modality and long-term outcomes among critically ill adults with acute kidney injury: a retrospective cohort study. Crit Care Med. 2014;42(4):868-77.

95. Liang KV, Sileanu FE, Clermont G, Murugan R, Pike F, Palevsky PM, et al. Modality of RRT and recovery of kidney function after AKI in patients surviving to hospital discharge. Clin J Am Soc Nephrol. 2016;11(1):30-8.

96. Bonnassieux M, Duclos A, Schneider AG, Schmidt A, Bénard S, Cancalon $C$, et al. Renal replacement therapy modality in the ICU and renal recovery at hospital discharge. Crit Care Med. 2018;46(2):e102-10.

97. Schneider AG, Bellomo R, Bagshaw SM, Glassford NJ, Lo S, Jun M, et al. Choice of renal replacement therapy modality and dialysis dependence after acute kidney injury: a systematic review and meta-analysis. Intensive Care Med. 2013;39(6):987-97.

98. Gaudry S, Hajage D, Schortgen F, Martin-Lefevre L, Pons B, Boulet E, et al. Initiation strategies for renal-replacement therapy in the intensive care unit. N Engl J Med. 2016;375(2):122-33.

99. Barbar SD, Clere-Jehl R, Bourredjem A, Hernu R, Montini F, Bruyère $R$, et al. Timing of renal-replacement therapy in patients with acute kidney injury and sepsis. N Engl J Med. 2018;379(15):1431-42.

100. Gaudry S, Hajage D, Benichou N, Chaïbi K, Barbar S, Zarbock A, et al. Delayed versus early initiation of renal replacement therapy for severe acute kidney injury: a systematic review and individual patient data meta-analysis of randomised clinical trials. Lancet Lond Engl. 2020;395(10235):1506-15.

101. STARRT-AKI Investigators, Canadian Critical Care Trials Group, Australian and New Zealand Intensive Care Society Clinical Trials Group, United Kingdom Critical Care Research Group, Canadian Nephrology Trials Network, Irish Critical Care Trials Group, et al. Timing of initiation of renal-replacement therapy in acute kidney injury. N Engl J Med. 2020:383(3):240-51.

102. Zarbock A, Kellum JA, Schmidt C, Van Aken H, Wempe C, Pavenstädt H, et al. Effect of early vs delayed initiation of renal replacement therapy on mortality in critically III patients with acute kidney injury: the ELAIN Randomized Clinical Trial. JAMA. 2016;315(20):2190-9.

103. Meersch M, Küllmar M, Schmidt C, Gerss J, Weinhage T, Margraf A, et al. Long-term clinical outcomes after early initiation of rrt in critically III patients with AKI. J Am Soc Nephrol. 2018;29(3):1011-9.

104. Colvin RB. Chronic allograft nephropathy. N Engl J Med. 2003;349(24):2288-90.

105. Kang HM, Ahn SH, Choi P, Ko Y-A, Han SH, Chinga F, et al. Defective fatty acid oxidation in renal tubular epithelial cells has a key role in kidney fibrosis development. Nat Med. 2015;21(1):37-46.

106. Yang L, Besschetnova TY, Brooks CR, Shah JV, Bonventre JV. Epithelial cell cycle arrest in G2/M mediates kidney fibrosis after injury. Nat Med. 2010;16(5):535-43.

107. Bechtel W, McGoohan S, Zeisberg EM, Müller GA, Kalbacher H, Salant $D J$, et al. Methylation determines fibroblast activation and fibrogenesis in the kidney. Nat Med. 2010;16(5):544-50. 
108. Chen J, Chen J-K, Nagai K, Plieth D, Tan M, Lee T-C, et al. EGFR signaling promotes TGF $\beta$-dependent renal fibrosis. J Am Soc Nephrol. 2012;23(2):215-24.

109. Xu Z, Li W, Han J, Zou C, Huang W, Yu W, et al. Angiotensin II induces kidney inflammatory injury and fibrosis through binding to myeloid differentiation protein-2 (MD2). Sci Rep. 2017;21(7):44911.

110. Casare FAM, Thieme K, Costa-Pessoa JM, Rossoni LV, Couto GK Fernandes FB, et al. Renovascular remodeling and renal injury after extended angiotensin II infusion. Am J Physiol - Ren Physiol. 2016;310(11):F1295-307.

111. Álvarez Á, Cerdá-Nicolás M, Nabah YNA, Mata M, Issekutz AC, Panés J, et al. Direct evidence of leukocyte adhesion in arterioles by angiotensin II. Blood. 2004;104(2):402-8.

112. Antonucci E, Gleeson PJ, Annoni F, Agosta S, Orlando S, Taccone FS, et al. Angiotensin II in refractory septic shock. Shock Augusta Ga. 2017:47(5):560-6.

113. Khanna A, English SW, Wang XS, Ham K, Tumlin J, Szerlip H, et al. Angiotensin II for the treatment of vasodilatory shock. N Engl J Med. 2017;377(5):419-30

114. Jamme M, Hertig A, Rafat C. Angiotensin II for the treatment of vasodilatory shock. N Engl J Med. 2017;377(26):2603.

115. Gayat E, Hollinger A, Cariou A, Deye N, Vieillard-Baron A, Jaber S, et al. Impact of angiotensin-converting enzyme inhibitors or receptor blockers on post-ICU discharge outcome in patients with acute kidney injury. Intensive Care Med. 2018:44(5):598-605.

116. Brar S, Ye F, James MT, Hemmelgarn B, Klarenbach S, Pannu N, et al. Association of angiotensin-converting enzyme inhibitor or angiotensin receptor blocker use with outcomes after acute kidney injury. JAMA Intern Med. 2018;178(12):1681-90.

117. Scarton M, Oppenheimer A, Chaïbi K, Dreyfuss D, Gaudry S. Reninangiotensin-aldosterone system blockers after KDIGO stage 3 acute kidney injury: use and impact on 2-year mortality in the AKIKI trial. Crit Care Lond Engl. 2019:23(1):148.

118. Hsu C-Y, Liu KD, Yang J, Glidden DV, Tan TC, Pravoverov L, et al. Reninangiotensin system blockade after acute kidney injury (AKI) and risk of recurrent AKI. Clin J Am Soc Nephrol CJASN. 2020;15(1):26-34.

119. Siew ED, Parr SK, Abdel-Kader K, Perkins AM, Greevy RA, Vincz AJ, et al. Renin-angiotensin aldosterone inhibitor use at hospital discharge among patients with moderate to severe acute kidney injury and its association with recurrent acute kidney injury and mortality. Kidney Int. 2020. http://www.sciencedirect.com/science/article/pii/S008525382 0310656. Accessed 13 Sept 2020.

120. Saran R, Li Y, Robinson B, Abbott KC, Agodoa LYC, Ayanian J, et al. US renal data system 2015 annual data report: epidemiology of kidney disease in the United States. Am J Kidney Dis Off J Natl Kidney Found. 2016:67(3 Suppl 1):Svii, S1-305.

121. Siew ED, Peterson JF, Eden SK, Hung AM, SperoffT, Ikizler TA, et al. Outpatient nephrology referral rates after acute kidney injury. J Am Soc Nephrol JASN. 2012;23(2):305-12.
122. Karsanji DJ, Pannu N, Manns BJ, Hemmelgarn BR, Tan Z, Jindal K, et al. Disparity between nephrologists' opinions and contemporary practices for community follow-up after AKI hospitalization. Clin J Am Soc Nephrol. 2017;12(11):1753-61.

123. Harel Z, Wald R, Bargman JM, Mamdani M, Etchells E, Garg AX, et al. Nephrologist follow-up improves all-cause mortality of severe acute kidney injury survivors. Kidney Int. 2013;83(5):901-8.

124. Geri G, Stengel B, Jacquelinet C, Aegerter P, Massy ZA, Vieillard-Baron A, et al. Prediction of chronic kidney disease after acute kidney injury in ICU patients: study protocol for the PREDICT multicenter prospective observational study. Ann Intensive Care. 2018;8(1):77.

125. Tomašev N, Glorot X, Rae JW, Zielinski M, Askham H, Saraiva A, et al. A clinically applicable approach to continuous prediction of future acute kidney injury. Nature. 2019;572(7767):116-9.

126. Flechet M, Falini S, Bonetti C, Güiza F, Schetz M, Van den Berghe G, et al. Machine learning versus physicians' prediction of acute kidney injury in critically ill adults: a prospective evaluation of the AKI predictor. Crit Care Lond Engl. 2019:23(1):282.

127. Ibrahim NE, McCarthy CP, Shrestha S, Gaggin HK, Mukai R, Magaret CA, et al. A clinical, proteomics, and artificial intelligence-driven model to predict acute kidney injury in patients undergoing coronary angiography. Clin Cardiol. 2019;42(2):292-8

128. Rashidi HH, Sen S, Palmieri TL, Blackmon T, Wajda J, Tran NK. Early recognition of burn- and trauma-related acute kidney injury: a pilot comparison of machine learning techniques. Sci Rep. 2020;10(1):205.

129. Lin P-C, Huang H-C, Komorowski M, Lin W-K, Chang C-M, Chen K-T, et al. A machine learning approach for predicting urine output after fluid administration. Comput Methods Programs Biomed. 2019;177:155-9.

130. Moledina DG, Parikh CR. Phenotyping of acute kidney injury: beyond serum creatinine. Semin Nephrol. 2018;38(1):3-11.

131. Kashani K, Al-Khafaji A, Ardiles T, Artigas A, Bagshaw SM, Bell M, et al. Discovery and validation of cell cycle arrest biomarkers in human acute kidney injury. Crit Care. 2013;17(1):R25.

132. Hoste E, Bihorac A, Al-Khafaji A, Ortega LM, Ostermann M, Haase M, et al. Identification and validation of biomarkers of persistent acute kidney injury: the RUBY study. Intensive Care Med. 2020. https://doi. org/10.1007/s00134-019-05919-0.

133. Chousterman BG, Boissonnas A, Poupel L, Baudesson de Chanville C, Adam J, Tabibzadeh N, et al. Ly6Chigh monocytes protect against kidney damage during sepsis via a CX3CR1-dependent adhesion mechanism. J Am Soc Nephrol JASN. 2016;27(3):792-803.

\section{Publisher's Note}

Springer Nature remains neutral with regard to jurisdictional claims in published maps and institutional affiliations.

\section{Submit your manuscript to a SpringerOpen ${ }^{\odot}$ journal and benefit from:}

- Convenient online submission

- Rigorous peer review

- Open access: articles freely available online

- High visibility within the field

- Retaining the copyright to your article

Submit your next manuscript at springeropen.com 